\title{
GIS-Based Evaluation of Soybean Growing Areas Suitability in China
}

\author{
Wenying He, Sen Yang, Rui Guo, Yaxiong Chen, Weihong Zhou, \\ Chaojie Jia, and Guojun Sun*
}
MOE Key Laboratory of Arid and Grassland Ecology, School of Life Science, Lanzhou University, Lanzhou, Gansu Province, P.R. China 730000
Hewenying1227@126. com

\begin{abstract}
In this study, the suitable areas for soybean in China were presented by GIS-based Multi-Criteria Evaluation (MCE) approach. We collected datas of environmental conditions and soybean growth associated factors, then, by the GIS technology we established spatial database of regional weather, topography, and soil conditions. Using the Spatial Analyst, the Spatial Interpolation, the Reclassification and the Weighted Overlay of ARCGIS9.2 operated to the database. Then the suitable criteria map of soybean in China was created, and the potential suitability of soybean planting areas was evaluated. The results showing 5,960,271 $\mathrm{km}^{2}$ of areas are fit for spring soybean and 5,286,643 $\mathrm{km}^{2}$ of areas are fit for summer soybean in the Northeast Plain, the Huang-Huai Plain and the Yangtze River Delta, in addition, there are lots of scattered suitable areas for soybean cultivation. This present study was aimed to provide some value references for Government formulating policies on the adjustment of industrial structure, and some reasonable guidance for farmers cultivating the agricultural products, more importantly, to achieve the purpose of utilizing natural resources reasonably.
\end{abstract}

Keywords: soybean; MCE; GIS; Suitable Level.

\section{Introduction}

China has the longest history of the cultivation of soybeans, which is over 5000 years [1]. The distribution of soybeans in China is extremely extensive, and before the 1950s, China had been the world's leading soybean producer all the time, not only having a surplus in self-sufficiency but with large quantities of soybeans exported abroad [2]. However, since 1996, China's import of soybeans has been increased year after year, having currently developed into the largest soybean importer in the world [3]. Because soybeans are of high nutritional values and healthcare functions, they are increasingly appreciated by the public, resulting in a boost in the demand [4]. While the current situation of the soybean in China shows that the soybeans are of low oil extraction rate and yield but of high cost, having difficulty in the competition with the imported soybeans. It can be said that Chinese soybeans are now "besieged on all sides and involved in trouble."

* Corresponding author. 
When digging into the reasons, it's found that the real shock to Chinese soybeans is the development of Chinese agriculture which is of low production input and productivity as well as poor competitiveness. Meanwhile, China is seriously lacking in the investment in soybean research and the promotion of soybean technology. Although the breeds of corn, rice and wheat have been updated dozens of times throughout the country, many farmers in the main producing areas of soybeans are still cultivating the old soybean breed of many years ago [5].

Currently, the soybean research in China is mainly focused on its nutrition and healthcare, in addition to the study of physiology, breeding and other aspects. Since there's a lack of macro research, it's necessary to develop the soybean mapping. In this research, the Multi-Criteria Evaluation (MCE) of GIS will be adopted to evaluate the potentially suitable planting areas for Chinese soybeans. The so-called MCE-GIS method is to employ reference standard and its weights in the assistance of the decision-maker to select the most appropriate option and solve a practical problem (objective) with an evaluation matrix [6]. In addition, the result could be visualized. This combination of MCE and GIS has been widely used in the evaluation and decision analysis of breed suitability. And in the central Mexico, the potential producing areas of corns, potatoes and oats have been assessed in the adoption of MCE method [7]. In this research the MCE method is carried out across the county to evaluate the potentially suitable planting areas of the crops, and to assess the potential producing area of Chinese soybeans. It is hoped that the research result could provide a visual guidance to the reasonable cultivation and the distribution planning of soybeans in China, helping to solve the existing cultivating problems of Chinese soybeans and to improve the efficiency of land use. This would also facilitate the instruction of farmers on agricultural production, increase the decision efficiency of the government and eliminate the blindness in agricultural investment, to further boost the investment incomes and the living standards of the farmers.

\section{Methods}

The main steps in the evaluation of the potentially suitable planting areas of Chinese soybeans are as follows: (1) to select the climate and soil factors that are essential to the growth of soybeans in reference to the opinions of the experts and relevant literature [8-15]. (2) to establish a database for the factors selected nationwide. In ArcGIS9.2, using spatial analysis module and Kriging spatial interpolation module to convert the raw data of each impact factor into raster layer. (3) to re-classify the raster layers of all the variables with re-classification module in the integration of the experts' opinions so as to get the suitable hierarchy map of each factor that affecting the growth of soybeans. (4) to adopt Analytic Hierarchy Process (AHP), in which all the factors will be compared and scored by agriculture expert in pairs to calculate the weight of each impact factor. (5) to carry out weighted superposition of the suitable hierarchy map of each factor in the use of the weighted superposition module in ArcGIS9.2, and finally adding in the information of land use/ land cover, together with the national province boundaries to develop the map of the potentially suitable planting areas of soybeans across China. 


\subsection{Research Area and Research Object}

The research area covers the approximate 9.6 million square kilometers of the entire land area of China, which stretches out to the north of the center of Heilongiiang at the town of Mohe $\left(53^{\circ} 31^{\prime} \mathrm{N}\right)$, to the south of the South Sea Island $\left(4^{\circ} 15^{\prime} \mathrm{N}\right)$, to the west of the Pamirs $\left(73^{\circ} 40^{\prime} \mathrm{E}\right)$, and to the east of the confluence of Heilongjiang and the Ussuri $\left(135^{\circ} 05^{\prime} \mathrm{E}\right)$. In this research, soybeans are divided into summer soybeans and spring soybeans according to different time of sowing and harvesting in order to improve the accuracy of the experiment.

\subsection{Selection of Evaluation Factors}

The selection of evaluation factors mainly conforms to the following principles: a. dominance-the selection of major factors that affect the growth of soybeans; b. difference-the selection of factors that have significant difference and could create critical value; c. incompatibility (independence)—-the selected factors shouldn't have correlations; d. operability - the relevant resources of the selected factors should be easy to get [16].

On this basis, the selection of factors that affect the distribution of soybeans includes: accumulated temperature at the whole growth period $\left(\geq 10^{\circ} \mathrm{C}\right)$, precipitation at the whole growth period, sunshine duration at the whole growth period, the lowest temperature at the whole growth period (May), the highest temperature at the whole growth period (August), PH value of soil, field moisture capacity and type of soil.

\subsection{Establishment of Database}

\subsubsection{Topographic Database}

The national 1:250 thousand contour data are provided by the National Mapping Bureau, and the national digital elevation model (DEM) is developed in ArcGIS9.2. Firstly, the original contour data are converted into Triangulated Irregular Network (TIN) in ArcInfo, and then further into DEM to draw elevation information. Finally, the grid size is confined to $1000 \mathrm{~m} \times 1000 \mathrm{~m}$ in the use of Albers projection.

\subsubsection{Meteorological Database}

The multi-year average climatic data at 749 stations across China are provided by the Central Meteorological Bureau, recorded from 1971 to 2008. Making vectorization of the climatic data in ArcGIS9.2 could get the vector data of the coverage at the nationwide 749 stations. And then making spatial interpolation of these vector data in ArcMap and inserting the climatic data at the research area to get raster layers of each factor. Finally, the grid size is confined to $1000 \mathrm{~m} \times 1000 \mathrm{~m}$ in the use of IDW interpolation (Inverse Distance Weighted) and Albers projection.

Before the vectorization of the original data, origin7.5 is used to obtain a multiple regression equation of longitude, latitude and altitude, which is used to calculate the climatic data at each weather station and its difference with the original climatic data. 
Table 1. Specific level per factor for the spring soybean

\begin{tabular}{llllll}
\hline \multirow{2}{*}{ Factor } & \multicolumn{5}{c}{ Level of suitability } \\
\cline { 2 - 6 } & Very High & High & Medium & Low & Very Low \\
\hline Accumulate temperature $\left(\geqslant 10^{\circ} \mathrm{C}\right)$ & $3300-2400$ & $2400-2200$ & $2200-1900$ & $>4000$ & $<1900$ \\
Precipitation $(\mathrm{mm})$ & $540-370$ & $370-320$ or $540-1000$ & $320-250$ or $>1000$ & $320-180$ & $<180$ \\
Minimum temperature $\left({ }^{\circ} \mathrm{C}\right)$ & $22-20$ & $20-18$ & $18-10$ & $10-4$ & $<4$ \\
Maximum temperature $\left({ }^{\circ} \mathrm{C}\right)$ & $25-22$ & $22-18$ & $18-16$ & $16-4$ & $<14$ or $>25$ \\
Sunshine hours $(\mathrm{h})$ & $750-700$ & $750-1200$ & $1200-1350$ & $1350-1700$ & $<700$ \\
field water capacity & $0.80-0.80$ & $0.7-0.5$ & $0.5-04$ & $0.4-0.2$ & $<0.2$ \\
Soil type & Loam & Sandy/Clay/Silt loam & Sandy/Silt clay & Other class & Sandy \\
Soil pH & $6.0-6.5$ & $6.5-7.0$ & $7.0-7.5$ & $7.5-7.8$ & $<6.0$ or $>7.8$ \\
\hline
\end{tabular}

Table 2. Specific level per factor for the summer soybean

\begin{tabular}{cccccc}
\hline Factor & \multicolumn{5}{c}{ Level of suitability } \\
\cline { 2 - 6 } & Very High & High & Medium & Low & Very Low \\
\hline Accumulate & $3400-2800$ & $2800-2400$ or $>3400$ & $2400-2000$ & $2000-1000$ & $<1900$ \\
Precipitation(mm) & $650-360$ & $650-1000$ & $360-250$ & $>1000$ & $<250$ \\
Minimum temperature $\left({ }^{\circ} \mathrm{C}\right)$ & $30-20$ & $20-15$ & $15-10$ & $10-8$ & $<8$ \\
Maximum temperature $\left({ }^{\circ} \mathrm{C}\right)$ & $28-25$ & $25-22$ & $22-18$ & $18-16$ & $<16$ \\
Sunshine hours $(\mathrm{h})$ & $750-700$ & $750-1200$ & $1200-1350$ & $1350-1700$ & $<700$ or $>1700$ \\
field water capacity & $0.80-0.80$ & $0.7-0.5$ & $0.5-04$ & $0.4-0.2$ & $<0.2$ \\
Soil type & Loam & Sandy/Clay/Silt loam & Sandy/Silt clay & Other class & Sandy \\
Soil pH & $6.0-6.5$ & $6.5-7.0$ & $7.0-7.5$ & $7.5-7.8$ & $<6.0$ or $>7.8$ \\
\hline
\end{tabular}

And this difference should be vectorized. Then the regression coefficient will be adopted in the Spatial Analyst module of ArcGIS9.2 to make grid computing, the result of which will be overlapped with the vector data. In this way, the impacts of longitude, latitude and altitude are all taken into consideration, so the interpolation would be more accurate.

\subsubsection{Soil Database}

The national 1: 1 million soil type data are provided by Nanjing Institute of Soil Science. Firstly, the data are sampled into 99034 point data, to which spatial Kriging interpolation are carried out in ArcGIS9.2, and in this way the raster layer of soil is obtained. Then in combination with Soil Species of China, soil texture, soil PH value and other information about different types of soil are extracted, which are then used in ArcGIS9.2 to create the raster layers of each type of soil. Finally, the grid size is confined to $1000 \mathrm{~m} \times 1000 \mathrm{~m}$ in the use of Albers projection.

\subsection{Re-Classification}

On the basis of the established database, the suitability of climatic and soil data is divided in accordance with the growing conditions of soybeans into five categories: 


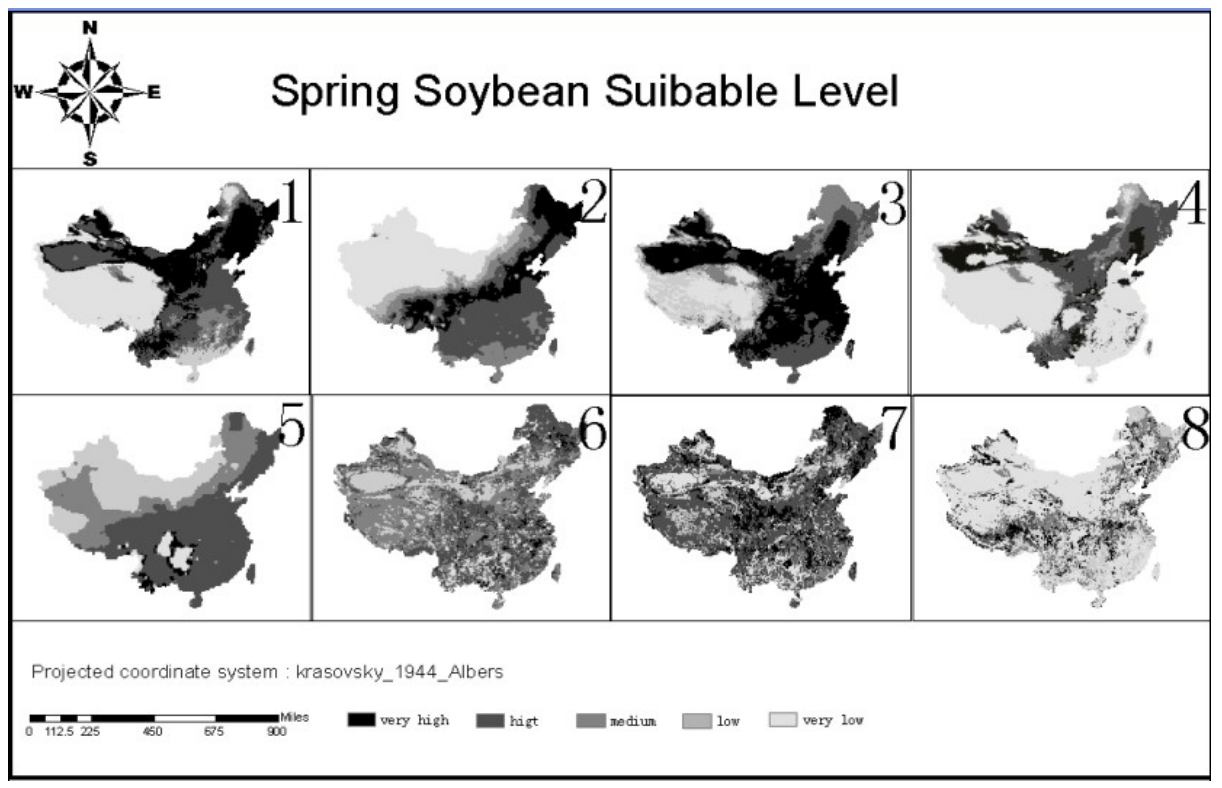

Fig. 1. Factor map for spring soybean, including suitability levels for each factors: $1=$ Accumulate temperature $\left(\geq 10^{\circ} \mathrm{C}\right) ; 2=$ Precipitation; $3=$ Minimum temperature in growing season $\left({ }^{\circ} \mathrm{C}\right) ; 4=$ Maximum temperature in growing season $\left({ }^{\circ} \mathrm{C}\right) ; 5=$ Sunshine hours $(\mathrm{h}) ; 6=$ field water capacity; $7=$ Soil type; $8=$ Soil $\mathrm{Ph}$

highest, high, medium, low and minimum (five standards as shown in Table 1, Table 2). And then the map of the suitability of soybean factors is created through the re-classification in ArcGIS(Fig. 1, Fig. 2).

\subsection{Multi-criteria Evaluation (MCE)}

The relatively mature methods adopted in the confirmation of evaluation factors include DELPHI, AHP, regression analysis, grey relation degree, principal component analysis and so on. In this paper, AHP method is employed. It is a kind of paired comparison method put forward by Saaty (1977) in the context of decision making [17]. This simple, flexible and practical MCE method can be used in the quantitative analysis of qualitative problems. Firstly, agriculture experts are asked to compare and score the relative importance of factors at the same level in pairs (see Table 3), then the results will be calculated in MATLAB2006 to obtain the weight value which represents the relative importance of factors at the same level, and finally the relative weight value of all factors will be computed and rearranged according to the general ordering of all levels.

The calculated weight coefficients respectively are: accumulated temperature of 0.2657 , precipitation of 0.2744 , the lowest temperature of 0.1396 at the whole growth period, the highest temperature of 0.1633 at the whole growth period, sunshine duration of 0.0505 , field moisture capacity of 0.0410 , soil $\mathrm{PH}$ value of 0.0328 and soil texture of 
0.0328. The weighted superposition should be carried out on these eight factors in the use of weight coefficients to obtain the hierarchy map, which should then be overlapped with the land use map that has deducted the areas of water, sand, desert and high cold wasteland to get the potentially suitable planting areas of soybeans in China (Fig. 3, Fig. 4).

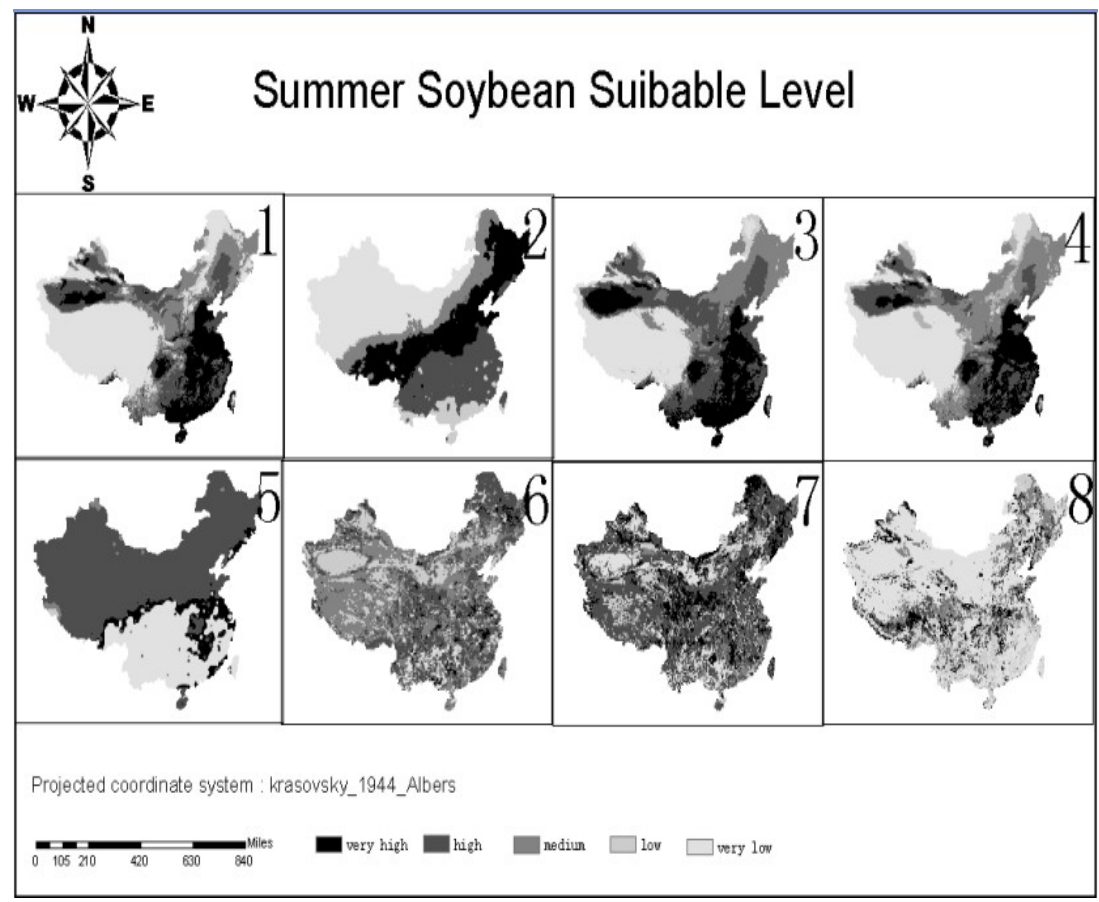

Fig. 2. Factor map for summer soybean, including suitability levels for each factor: $1=$ Accumulate temperature $\left(\geq 10^{\circ} \mathrm{C}\right) ; 2=$ Precipitation; $3=$ Minimum temperature in growing season $\left({ }^{\circ} \mathrm{C}\right) ; 4=$ Maximum temperature in growing season $\left({ }^{\circ} \mathrm{C}\right) ; 5=$ Sunshine hours $(\mathrm{h}) ; 6=$ field water capacity; $7=$ Soil type; $8=$ Soil $\mathrm{pH}$

Table 3. Analysis of system-level indicators and the results of the comparison: AT = Accumulate temperature $\left(\geq 10^{\circ} \mathrm{C}\right), \mathrm{PR}=$ Precipitation, $\mathrm{MI}=\operatorname{Minimum}$ temperature $\left({ }^{\circ} \mathrm{C}\right), \mathrm{MA}=$ Maximum temperature $\left({ }^{\circ} \mathrm{C}\right), \mathrm{SH}=$ Sunshine hours, $\mathrm{WC}=$ field water capacity, $\mathrm{ST}=$ Soil type, $\mathrm{pH}=\mathrm{Soil} \mathrm{pH}$

\begin{tabular}{|c|c|c|c|c|c|c|c|c|}
\hline & AT & PR & MI & MA & SH & WC & ST & $\mathrm{PH}$ \\
\hline $\mathrm{AT}$ & 1 & $9 / 8$ & $3 / 2$ & $6 / 5$ & $6 / 1$ & $7 / 1$ & $8 / 1$ & $8 / 1$ \\
\hline PR & $8 / 9$ & 1 & $4 / 3$ & 75 & $7 / 1$ & $8 / 1$ & $9 / 1$ & $9 / 1$ \\
\hline MI & $2 / 3$ & $3 / 4$ & 1 & 23 & $2 / 1$ & $3 / 1$ & $4 / 1$ & $4 / 1$ \\
\hline MA & $5 / 6$ & $5 / 7$ & $3 / 2$ & 1 & $3 / 1$ & $4 / 1$ & $5 / 1$ & $5 / 1$ \\
\hline SH & $1 / 6$ & $1 / 7$ & $1 / 2$ & $1 / 3$ & 1 & $7 / 6$ & $9 / 6$ & $9 / 6$ \\
\hline WC & $1 / 7$ & $1 / 8$ & $1 / 3$ & $1 / 4$ & 67 & 1 & $9 / 7$ & $9 / 7$ \\
\hline ST & $1 / 8$ & $1 / 9$ & $1 / 4$ & $1 / 5$ & $6 / 7$ & $7 / 9$ & 1 & 1 \\
\hline $\mathrm{PH}$ & $1 / 8$ & $1 / 9$ & $1 / 4$ & $1 / 5$ & $6 / 7$ & $7 / 9$ & 1 & 1 \\
\hline
\end{tabular}




\section{Results and Discussions}

Potential distributing areas for Soybean as show as Fig. 3. If the levels of Very high, High and Medium are chosenas the suitable planting areas, the overall suitable area of Chinese springsoybeans is 5,960,271 km2, taking up 79\% of the total area and summer soybeans is $5,286,643 \mathrm{~km} 2$, taking up $70 \%$ of the total areas.

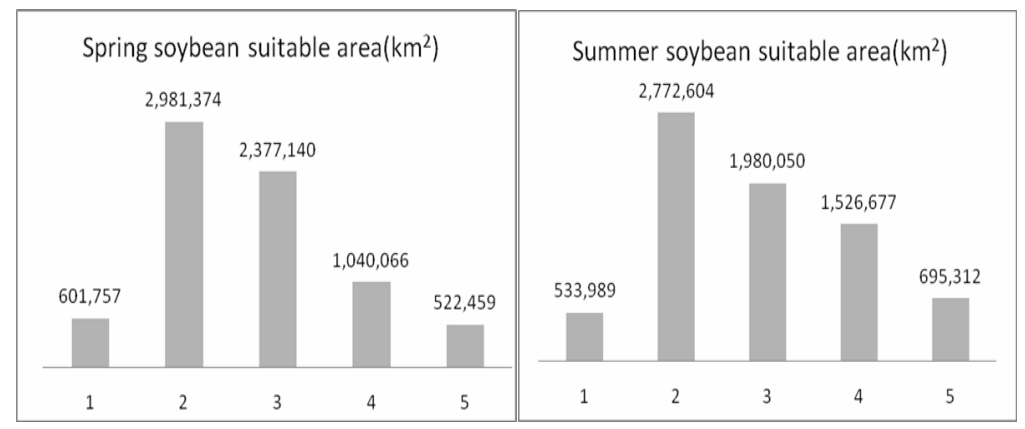

Fig. 3. The potential distributing area for soybean in China(1= Very High, $2=$ High, $3=$ Medium, 4=Low, 5=Very Low)

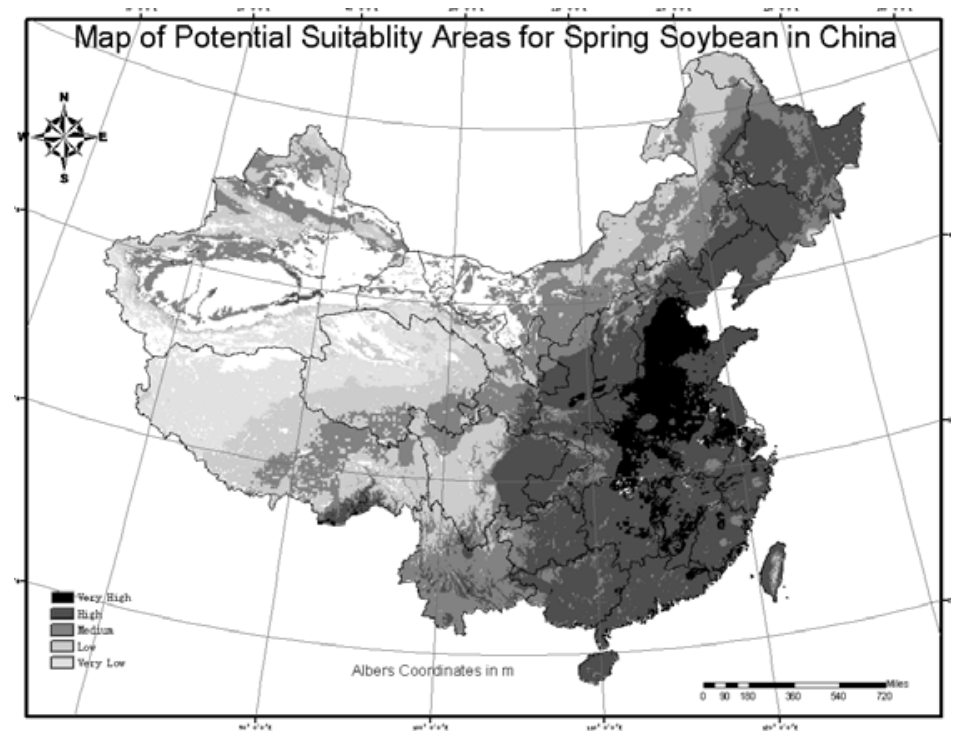

Fig. 4. Suitability map for spring soybean in China 


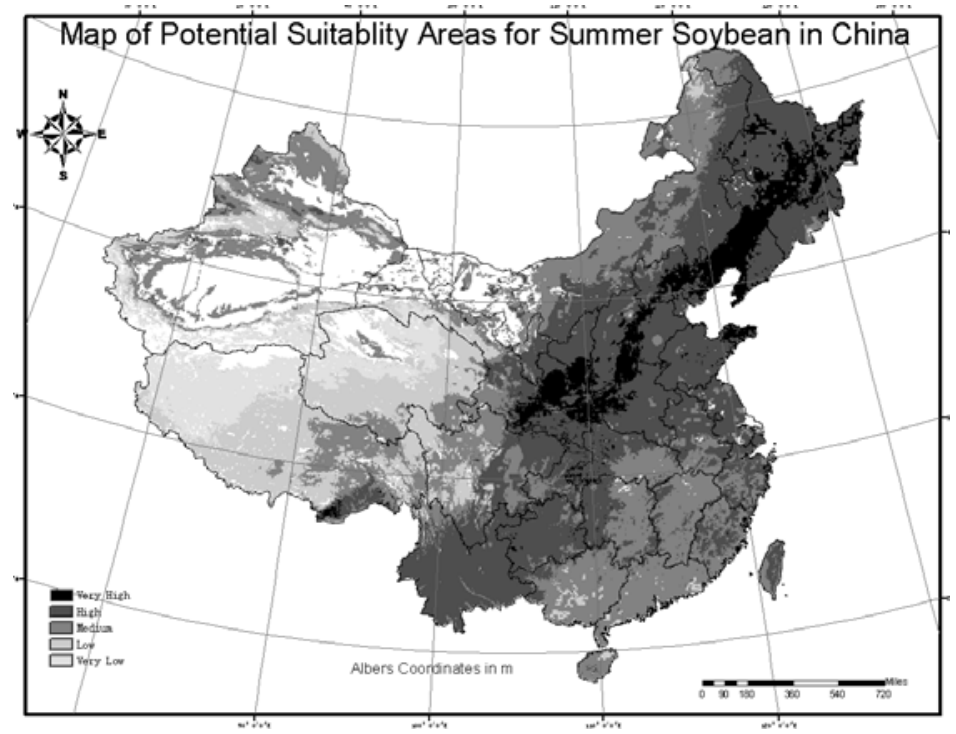

Fig. 5. Suitability map for summer soybean in China

As shown on Fig. 4 and Fig. 5, the most suitable planting areas of spring soybeans mainly distribute zonally over Heilongjiang, the central plain of Jilin, the southwest of Liaoning, the southeast of Shanxi, the central section of Shannxi, the southeast of Gansu, the west of Henan, the north of Hebei, Shantung Peninsula, Beijing and some parts of Hubei. While the most suitable planting areas of summer soybeans principally spread over the south of Beijing, Tianjin, the south of Hebei, south and north of Shantung, the east of Henan, the west of Shanxi, the north of Anhui, the central section of Hubei, south Jiangsu and some parts of Hunan, Chekiang, Fujian and Guangzhou, mainly the regions of abundant precipitation and sunshine in the Northeast Plain, the Huanghuaihai plain and the Middle and Lower Yangtze Valley Plain.

The optimum planting area for spring soybean in China is zonal distributed from northeast to southwest, mainly found in arid, semiarid, sub-humid-semiarid areas of China, for these areas have an arid climate and a long time sun light exposure. Meanwhile, these areas are the agriculture-pasture transition zone in north China, and most of the areas with extremely high suitability and high suitability are overlapped with the ecotone of China. Summer soybean is centered in costal humid, sub-humid zone where have many plains and abundant rainfall. It is mainly affected by the restrictions from accumulated temperature, sunshine duration and amount of precipitation which are just the primary factors to the soybean growing.

Since this is basically in line with the actual distribution of the cultivation of soybeans, it is demonstrated that this method is applicable to the division of the suitable planting areas of soybeans.

The evaluation of the potentially suitable planting areas of soybeans is an indispensable part of Chinese crop map system, having realized the visualization of the 
potentially suitable planting areas of Chinese soybeans and the suitable hierarchy. After the completion of the entire crop map system in the future, the internet would be should to provide visualization information about the distribution of crops in the provinces even in the counties and countries across China, filling the vacancy of online system of Chinese crops.

\section{Problems and Prospects}

The suitable planting areas of soybeans in this research are a kind of potential distribution, for the actual evaluation of the suitable planting areas of soybeans is likely to be affected by the micro topography, economic level, living tradition and other factors. Although there's a slight discrepancy between the potential distribution and the actual distribution, this research has roughly simulated the potentially suitable planting areas of soybeans in China.

In the next step of work, market demand and supply, price fluctuation and other factors will be further studied to consummate the distribution map of the suitable planting areas for soybeans; in addition, the yield model would also be integrated in the evaluation of the potential production capacity of soybeans. Meanwhile, the influence of climatic change on the distribution of the suitable planting areas of soybeans is also investigated. At last, this research evaluates the formation process of the components of yield, input, resource utilization, environmental load, potential pollution and so on, and it could also combine the economical analysis module to carry out marginal utility analysis of input and output, to form strategies that can replace the management measure and decision-making consultancy.

Chinese soybeans have the advantage of containing non-genetically modified ingredients, which confirms to the international consumption trend and should be made full use of to develop more effective cultivation planning, in the hope of boosting the yield of soybeans and improving China's production capacity of soybeans as well as the comprehensive competitiveness.

\section{References}

1. Zhu, Q., Gao, C., Chu, J.: The research of soybean cultivation history and value. Journal of Baicheng Normal College, 53-55 (1999)

2. Yu, D.: Enhance breeding of new cultivars for special use,promote the development of soybean production and processing. China Seeds, 10-11 (2002)

3. Yang, H.-q., Hao, Y.-k.: Historical review, current situation and development countermeasure of Chinese soybean. Guangdong Agricultural Sciences, 188-191 (2000)

4. Gen, Z.: Soybean Nutritional Value and Therapeutic Care. Food and Nutrition in China (3) (2002)

5. Zhu, X.: The development and countermeasures of China's soybean. Chinese Rural Economy, 27-33 (2003)

6. Rico, A.I.: Application of multicriteria evaluation to a spatial conflict in the urban fringe. ITC Msc thesis (2001) 
7. Ceballos-Silva, A., López-Blanco, J.: Delineation of suitable areas for crops using a Multi-Criteria Evaluation approach and Land use/cover mapping: a case study in Central Mexico. Agricultural Systems, 117-136 (2002)

8. Han, X., Qiao, Y., Zhang, Q., Wang, S., Song, C.: Effects of various soil moisture on the yield of soybean. Soybean Science, 269-272 (2003)

9. Sorte, N.V.: Effect of water logging on soybean critical growth stages. Journal of Soils and Crops, 141-144 (1995)

10. Li, W.: Grey Relational Analysis of Meteorological Factors on Soybean Growth and Yield. Heilongjiang Agricultural Sciences, 41-43 (2008)

11. Heatherly, L.G., Russell, W.J.: Vegetative development of soybeans grown on different soil types. Bioresource Technology, 2182-2188 (2006)

12. Yang, L.-F., Cai, Z.: Soil Respiration During a Soybean-Growing Season. Pedosphere, 192-200 (2006)

13. Bhatia, V.S., Singh, P., Wani, S.P., Chauhan, G.S., Kesava Rao, A.V.R., Mishra, A.K., Srinivas, K.: Analysis of potential yields and yield gaps of rainfed soybean in India using CROPGRO-Soybean model. Agricultural and Forest Meteorology 48, 1252-1265 (2008)

14. Burton, J.W.: Soyabean (Glycine max(L.) Merr.). Field Crops Research, 71-186 (1997)

15. del Carmen Vera-Diaz, M., Kaufmanna, R.K., Nepstad, D., Schlesingerc, P.: An interdisciplinary model of soybean yield in the Amazon Basin: The climatic, edaphic, and economic determinants. Ecological Economics, 420-431 (2008)

16. Liu, Y., Liu, Y., Xia, Z.: Land Suitability Evaluation Based on Fuzzy Comprehensive Judgement. Journal of Wu Han Technical University of Surveying and Mapping, 71-75 (1995)

17. Eastman, J.R., Jin, W., Kyem, A.K., Toledano, J.: Raster procedures for multi-criteria/ multiobjective decisions. Photogrammetric Engineering and Remote Sensing 61(5), 539-547 (1995) 